\title{
Problems and Suggestions on Bicycle Sharing from the Perspective of Law
}

\author{
Heting Sun
}

School of Politics and Administration,Wuhan University Of Technology, Wuhan ,430063, China; 569542267@qq.com

\author{
Keywords: Bicycle Sharing, Legal Perspective, Criminal Law, Property Law, Road Traffic Safety \\ Law
}

\begin{abstract}
As a new way of "Internet + Transportation", the bicycle sharing has occupied an important place in people's daily lives by the convenience of their leasing and return, the simplicity of payment and the characteristics of green lifestyle. However, due to road traffic conditions, urban environment, government regulation and the quality of different users, there are many problems in its actual operation. In this paper, the author analyzes the legal nature of the bicycles, based on the illegal possession, improper parking, improper use, deposit and many other problems. At the same time, the author puts forward the relevant suggestions
\end{abstract}

\section{Introduction}

Based on the definition that sharing bicycle is perceived as one new kind of "Internet plus" traveling pattern in which the users shall pay a certain amount of deposit in advance according to the regulations and pay rent and return in accordance with the service time, it is stipulated in Article 212 of Contract Law that "The lease contract is a contract that the lessor delivers the leased property to the lessee to use and benefit, and the lessee shall pay the rents". It can be seen that the business model of sharing bicycles is still a lease contract relationship in essence. And on this basis, the paper is going to analyze the existing problems.

According to Analysis Report of Sharing Bike Industry Development in China published by Trustdata Network in August 2017, there have been 32 million sharing bike users by June 2017 and the daily usage peaks nearly 18 million times in June. The frequency of utilization is basically leveling off to the vehicles for trips, and it is gradually spreading to the second and third-tier cities while maintaining the user adhesiveness in the first-tier cities. It is implied that the brand new "Internet plus" traveling model to address "the last kilometer" has make great differences on the daily life of urban residents owing to its various characteristics like the "Non-stake" convenience between leasing and returning, intelligence, the simple way of payment and the green lifestyle. However, the factors such as road traffic conditions, complicated urban environment, government attention and the user's quality have triggered a variety of problems in the actual operation management of sharing bicycles while we are enjoying the convenience it provides, which has been the great concern for the society.

\section{The Legal Issues of Sharing Bicycles}

The definition of the lease contract indicates that both parties including the leaser and lessee of shared bicycles shall undertake the responsibilities and obligations of their own. And their different evasions on them have produced the legal problems on different aspects. In the following, the author will focus on different subjects and elaborate from the three aspects which are separately the damaged shared features, the problems involved in legislation in the use and the deposit issues, so as to analyze the legal relationship in an objective way on the empirical basis.

\subsection{Damage to Its Shared Features}

The sharing features of the bicycles to be shared can be defined as the transferred right of use within a certain period, but keeping the lessor's ownership. Accordingly, the behavior of the damaged 
sharing features is divided into the following three situations, including the destroyed bicycles, unlawful possession, shared passwords and the plate number to be blocked or damaged. In the following part, the author will elaborate on these three situations respectively.

\subsubsection{Destroyed Bicycles}

At the beginning of this year, the man-made sabotage on bicycles occurred successively in Guangzhou and Shanghai. In January 2017, there were about 500 shared bicycles from the different operators piled up into two hills with the height ranging from 2 to 3 meters in Xiashan Park of Shekou, Shenzhen, resulting the citizens' failure in using them. Hundreds of bicycles including Bluegogo, Mobike and OFO are stacked viciously by the unidentified people. Many of them have been deliberately damaged, in which some of bicycle wheels are rolled, some fail work owing to the obviously loose brakes and frame, and others piled at the bottom have been severely deformed. In terms of the deliberate destruction of shared bicycles, it is stipulated in Article 49 of Law of Punishment for Public Security and Administration that in case the relatively minor circumstances, those involved in theft, fraud, plunder, robbery, racketeering or intentional damage to public and private property shall be detained for more than 5 days and less than ten days, and also may be fined less than five hundred yuan. And more than ten days and less than fifteen days of criminal detention shall be sentenced for the serious circumstances, and it may impose a fine of less than one thousand yuan. If the man-made destroyed shared bicycle worthy of 5000 yuan by judicial expertise, it is written in Article 275 of Criminal Law that "Those involved in the serious circumstances including intentional destruction of public and private property as well as the large amount shall be sentenced to fixed-term imprisonment of no more than 3 years, criminal detention or imposed fines. And those involved in huge amount or the other serious circumstances shall be sentenced to fixed-term imprisonment of not less than 3 years but not more than 7 years. In this regard, he may be faced with the criminal penalties.

\subsubsection{Unlawful Possession}

On the issue of illegal possession of shared bicycles, there are two situations in accordance with their subjective will:

The first one is that he takes the possession without stealing. In other words, the shared bicycles can be only used by him in the manners like private lock or hiding, but the rental costs still will be paid by scanning the QR code in the use. Such kind of illegal user still has a rental relationship with a bicycle company every time he uses the vehicle, except that the behavior of locking makes it unlikely for others to rent the vehicles. It is perceived as the infringement of the company's property rights and one civil trespass, but it shall not be identified as theft.

The second one is to transform it completely for illegal appropriation. In the course of coming home from work, one villager named Lv in Chengdu moved the bicycle park on the road home and then cut the lock and painted the vehicle body and the cushion to make it into the bicycle of his own. The staff in Public Security Bureau of Longquanyi District investigated this case and the suspect Lv confessed to stealing and destroying the shared bicycles. On February 28th 2017, it was heard in the People's Court of Longquanyi District in Chengdu and the suspect Lv was sentenced to detention for larceny for 3 months and imposed fines of 1000 yuan in court. The lessee never paying the rents for using the shared bicycles by destroying the original lock and adding the private lock and even maliciously demolishing and modifying the vehicles as the suspect Lv from Chendu did shall be presumed as the intention of illegal possession and shall be identified as the "theft act". It is stipulated in Article 49 of Law of Punishment for Public Security and Administration that "In case the relatively minor circumstances, those involved in theft, fraud, plunder, robbery, racketeering or intentional damage to public and private property shall be detained for more than 5 days and less than ten days, and also may be fined less than five hundred yuan. And more than ten days and less than fifteen days of criminal detention shall be sentenced for the serious circumstances, and it may impose a fine of less than one thousand yuan". In terms of the severe administrative penalty, it is stipulated in Article 264 of Criminal Law that "Those involved in the theft of a large amount of public and private property or the thefts for several times, burglary, larceny by carrying the weapons and pickpocketing shall be sentenced to fixed-term imprisonment of not less than three 
years and not more than ten years, and also shall be fined. And when the amount is extremely large or there are other serious circumstances, he shall be sentenced to fixed-term imprisonment of not less than ten years or life imprisonment, and also shall be imposed fines or confiscated properties". According to the Interpretation of Several Issues Concerning the Applicable Laws for Handling Criminal Cases of Theft (2013) by the Supreme People's Court and the Supreme People's Procuratorate, the starting point of larceny: the large amount shall be more than 1000 yuan and 3000 yuan above (All provinces shall formulate the accurate standards according to respective conditions), and the thefts occurring more than three times within two year are perceived as the "multiple thefts" and constitute a crime.

\subsubsection{Shared Passwords and Plate Number to be Blocked or Damaged}

The behaviors of shared passwords, the plate number to be blocked or damaged as well as the QR code never changed the ownership of shared bikes when it is not illegally possessed by persons. But it is these behaviors that the shared features of shared bicycles are destroyed, and its mobility and use ability are damaged without destroying the main function of the bicycles. Essentially, such kind of behavior has broken down the lessor's right to earnings.

\subsection{Legal Issues in the Use}

The author believes that there are several legal problems in the use of shared bicycles: the illegal use of those failing to meet the use conditions and the compensation for infringement of personal safety in the use, including the injuries of tenant caused by the problems emerging in the shared bicycles, the personal and property damage to the others in the use as well as the illegal parking after use. In the paper, they will be elaborated in the following.

\subsubsection{Illegal Use of Those Failing to Meet the Use Conditions}

On the afternoon of March 26th, the boy named Gao at the age of 11 unlocked the OFO shared bicycles which had been locked without upsetting the password and rode them on the road together with the other three minors. At 13 o'clock that day, Gao collided with the large bus registered the plate number of Shanghai D57982 and driven by the driver Wang when the four minors rode to the intersection of Tiantong Road, Qufu Road and North Zhejiang Road, leading to Gao's falling to the ground and extrusion as well as rolling after being brought into the front side of the large bus. He died in the hospital after the rescue in the same day. It can be seen from the above case that the children under 12 years of age to illegally ride the shared bicycles are the main parts of illegal use of unsatisfied conditions. And the restrictions of shared bikes like users in quantity, simple data feedback and non-face-to-face electronic data contract make it unlikely to o supervise the use of public bicycles for children under 12 years old. It is stipulated in Road Traffic Safety Law of the People's Republic of China that those riding bicycles and tricycles shall be more than 12 years old. Accordingly, the children under 12 should not use shared bicycles. In the case of the accident, the guardians shall also entail the corresponding responsibility for the damages apart from verifying the shared bike enterprise's possible responsibility for mismanagement and vehicle defects.

\subsubsection{Infringement of Personal and Property Safety in the use}

a. User's Personal Injury Caused by the Quality of Bicycles

Accompanying with the extended service time of shared bicycles in the market, the depreciation and parts consumption will be increasingly severe. Despite that the bicycle company will repair some of the vehicles have been applied for repair, it fails to guarantee the timeliness and comprehensiveness of maintenance and there are still potential security problems in the process of using.

On January 28, 2017, Mr. Feng rented a shared bicycle provided by OFO by scanning the QR code after his departure from the subway station. He met the downhill within 100 meters after his ride and the bike brake which suddenly failed triggered the out-of-control vehicle and falling down, resulting in the lacerated upper and lower lip and face as well as fractured nasal bridge. Mr. Feng took OFO Shared Bicycle Company to the court and required for a total of 20 thousand yuan as the compensation for medical expenses, loss of working hours, disability compensation, follow-up 
treatment, transportation costs and mental damage solatium. At present, the case has been formally accepted by the people's Court of Chaoyang District of Beijing.

From the case, it shows that the lease agreement is reached between users and bicycle company after the users unlocking the shared bicycles in the way of scanning the QR code, and the lease relationship with legal effect is formed for both parties. It is stipulated in Article 212 of Contract Law that "The lease contract is a contract that the lessor delivers the leased property to the lessee to use and benefit, and the lessee shall pay the rents". And according to Article 220, "The lessor shall perform the duty of maintenance of the leased property, except otherwise agreed by the parties concerned". As the lessor, the bicycle company shall be liable for providing the user or lessee with the safe and qualified leased items, and shall take the obligations of repairing the damaged leased property. The bicycle company shall be responsible for compensating the personal injury caused by the quality of the bicycle during riding.

\section{b. Collision with Other Vehicles or Pedestrians Leading to the Traffic Accidents}

The users shall call the police timely for the traffic accident caused by the collision no arising from the quality of bicycles between the user and other vehicles or pedestrians in the riding. And the scene shall be taken photos for evidence collection before the traffic police categorizing the responsibilities in the accident, and all parties shall be liable for the corresponding faults. The bicycle companies are not required to bear liability for related accidents.

c. Personal Injury Caused by Malicious Acts of Other Users

At present, the events of needles hidden on the seat or the tire of the bike emerge frequently and cause the personal injuries to parts of share bike users to a different extent. According to Article 43 of Law of Punishment for Public Security and Administration, "Those attacking or intentionally hurting others shall be detained for more than 5 days but less than 10 days and shall be imposed fines ranging from 200 yuan to 500 yuan. And those in the minor circumstances shall be detained for less than 5 days or fined less than 500 yuan". It is written in Article 234 of Criminal Law that "Those intentionally damaging the other's body shall be sentenced to fixed-term imprisonment of less than than 3 years, criminal detention or control. The offender committing the crime and leading to the serious injury of others shall be sentenced to fixed-term imprisonment of not less than 3 years but not more than 10 years. And those causing death to a person or leading to the serious disability arising from severe injury in the particularly cruel means shall be sentenced to fixed-term imprisonment of not less than 10 years, life imprisonment or death penalty. If there are otherwise provisions in this law, it shall be based on the stipulation". So the behavior causing the slight injury or above stipulated by Identification Standard of Personal Injury Severity to the users shall be sentenced to crime of intentional injury.

\subsubsection{Illegal Parking}

With the increasing shared bicycles, the bikes which have been widely used are parked on the street at random, which has occupied the blind sidewalk, triggered the severely affected traffic and made the roads more congested. There are circumstances that many scenic spots and parks have been captured by various bicycles in many parts of the country. The stacked shared bikes provided by the bicycle companies have not merely influenced the urban beauty but also brought inconvenience and potential dangers to the passing and safety of the crowd in the parks.

In this regard, the non-motor vehicles shall be parked in the prescribed place as stipulated by the Road Traffic Safety Law. In the case of no parking place to be designed, the non-motor vehicles shall be parked in the place without impeding other vehicles and pedestrians. The pedestrians, passengers, non-motor vehicle drivers violating the provisions about the road passage stipulated in the road traffic safety laws and regulations shall be warned or fined more than 5 yuan and less than 10 yuan. And the non-motor vehicle drivers refusing the fine penalty can be detained the vehicle. Additionally, it is also finalized in Regulations on City Appearance and Environmental Sanitation Management that no company and individual is allowed to stack materials and set up the buildings, structures or other facilities on both sides of the street or on public grounds. Therefore, all behaviors of randomly parking on both sides of the road and public places are regarded as the violation of laws and regulations. 


\subsection{Deposit Problem}

At present, the user shall pay the deposit of 199 yuan for using OFO shared bicycle and 299 yuan for Mobike. Additionally, all amounts are charged ranging from one yuan to several hundred yuan. And one user may download a variety of bike clients, pay more than one deposit and prepay multiple recharges. The bicycle companies make commitment to returning deposit but not the recharges in seconds. In fact, very few users apply for refunds immediately after using the vehicle, so the deposits are basically stored in the medium and long term. It is reported that merely the total deposit of sharing bicycles has reached 6 billion yuan and the funds for the company are astonishing. Coupled with the different recharges, a huge pool of funds has been shaped in the bicycle company.

As stipulated in Property Law and Security Law, the deposit is one kind of special pledge of movables. It is written in Article 208 of Property Law that the pledge of movables is "For the performance of the secured debt, the debtor or the third party give the possession to the creditor, and the creditor shall have the right to be given priority to the chattel in the case of the debtor failing to perform the due debts or the pledge agreed by the parties concerned emerging". The collection of deposit can both urge the proper use of bicycles and ensure the bicycle companies given the priority to compensation in the case of unmerited damages. In this regard, it is legal for the company to charge the deposits from the users to ensure they can use the bikes in the appropriate way. However, the deposit rules used between bicycle companies and users are quite different from that in the traditional lease contracts. The one-to-one correspondence relationship between the leased matters and deposit has been broken by shared bicycles, and the company charge the deposit for per capita instead of the number of rented bicycles, which has shaped the phenomenon of one bicycle to many users. Fundamentally, it arises from the refund systems of deposit issued by the bicycle companies. Under normal circumstances, one lease contract is performed after ending the use of bikes. After the lease contract as the main contract is completed, the corresponding guarantee contract shall be also ended, namely the users of bicycles shall be refunded immediately. But in fact, the deposit will be always controlled by the companies until the users apply for refund, and the one-to-many phenomenon between the bicycle and users' deposits comes into being. It may be suspected of improper possession of funds or even crime of illegal fund-raising. On June 13th.2017, Chongqing Zhanguo Science and Technology Co., Ltd. as the operator of Wukong Bicycle announced on its official Micro-blog that because of the adjustment of the company's strategy, it would officially stop providing support services for Wukong Bicycle and quit the bike sharing market since June of 2017. And Wukong Bicycle became the first industry to quit completely. In spite of the refunds to the users, they may not be refunded once the company fails in investing or it is eliminated by the fiercely competitive bicycle market after the deposits are used for investment or the other daily operations, thus causing the economic loss of the users.

\section{Countermeasures}

The frequent problems in the shared bicycles are triggered by multiple factors, and the paper focuses on researching how to put forward the practical and effective measures to solve various problems. In the following part, the author will specifically analyze the measures from all aspects, including the government, enterprises and users.

\subsection{Government shall Strengthen Guidance and Supervision.}

As the third party outside the government and users, government usually has more prominent advantages in the way of guiding and supervising the other side. In the industry 4.0 era of "Internet plus", the emergence and use of bicycle shall never go beyond the law. Accordingly, the government shall timely adapt at the legal level and enact the relevant administrative regulations while strengthening the supervision on various problems existing in the use of shared bicycles. For example, Shared Bicycle Service Specification, as the first domestic shared bike group standard which was implemented officially on October 1st in Shanghai, it plays a role in reorganizing the shared bicycles that are parked randomly in an effective way, regulating the behavior of sharing 
bike enterprises and maintaining the user experience and urban environment. In terms of users, the government shall bind up the use of bikes with the credit system construction, and the behavior of illegal use, parking and destruction of shared bicycles shall be recorded in the individual integrity archives. Furthermore, it shall more strengthen the legal publicity and education and the explanation of illegal cases and popularize the laws and regulations among the users, to enhance their thinking of ruling by laws and law-abiding consciousness.

\subsection{Enterprises shall Entail the Responsibility Actively}

As mentioned above, shared bicycle enterprises should undertake the corresponding responsibilities and obligations while having the power to collect rents and make profits. In the current context, the actual urban capacity is not considered by the companies in the delivery of shared bicycles. At the same time, the unstandardized parking has resulted in the excessive shared bicycles in the city, affected the urban appearance and penalized the traffic safety. So the enterprises are required to make a reasonable analysis on the urban capacity and delivery quantity in the course of operation and the bikes shall be equipped with a certain proportion of maintenance management personnel. The offline manual intervention shall be strengthened and the damaged vehicles shall be repaired or eliminated in the timely manner to guarantee the order and standardization in the operation of shared bicycles. In addition, they shall be active in explaining the possibility of illegal fund-raising in the huge deposit. When realizing the method of instant withdrawal of deposits, it shall seek for the reliable third party like governments in the custody and supervision of funds.

\subsection{Users shall Improve the Law-abiding Consciousness}

As the direct users of shared bicycles, all kinds of illegal behavior of users have most directly caused the frequent problems of sharing bicycles. Compared with enterprises, it appears more important to address the problems by actively undertaking the individual responsibility and obligation. In this regard, citizens are expected to actively learn relevant laws and regulations and understand the consequences and penalties caused by illegal activities, thus regulating the behavior of their own in accordance with the laws.

\section{Conclusion}

The shared bicycles as the emerging production of "Internet plus" will be undoubtedly confronted with all kinds of problems in the early stage of development and operation, but the "sharing economy" is not allowed to escape from the "rule-of-law economy". It is required to run and use the shared bicycles in accordance with the laws. Only the linkage among the three parties including government, enterprise and users can work out the multiple problems related to shared bicycles, thus making it possible for the increasingly standardized and orderly development of shared bicycles.

\section{References}

[1] Chu Beibei. On the shared bike platform to collect the deposit of the legal regulation - Take A share cycling platform as an example [J]. Legal Expo, 2017, (19): 27-28 + 5.

[2] Wang Mengyuan. Discussion on the legal responsibility of disrupting the shared cycling [J] .Jianghan Jiaotong Vocational College Journal, 2017,19 (02): 9-14.

[3] Zhai Ye-hu, Liu Tian-xin.Legal Problems of Shared Bicycle Rental [J] .Journal of Yangzhou University (Humanities and Social Sciences), 2017,21 (04): 39-46.

[4] Tian Mingyuan. Study on the legal issues of shared economic model [D]. Jilin University, 2016.

[5] Dong Chenghui. The Evolution of the Legal Mechanism of Shared Economy [J] .Learning and Practice, 2016, (12): 31-37. 